\title{
DEMOCRACIA, COOPERAÇÃO E CIDADANIA
}

\section{DEMOCRACY, COOPERATION AND CITIZENSHIP}

\section{GABRIEL BENEDITO ISSAAC CHALITA}

Professor e escritor. Tem dois doutorados - em Comunicação e Semiótica e em Direito; e dois mestrados - em Sociologia Política e em Filosofia do Direito. É professor na PUC-SP, na Universidade Presbiteriana Mackenzie, no IBMEC e na UNINOVE. É membro da Academia Brasileira de Educação e presidente da Academia Paulista de Letras.

WILSON LEVY

Doutor em Direito pela PUC-SP com estágio de pós-doutoramento pela Universidade Presbiteriana Mackenzie. Diretor do programa de pós-graduação em Cidades Inteligentes e Sustentáveis da UNINOVE.

\section{RESUMO}

Objetivo: O artigo aborda a relação entre democracia, cooperação e cidadania, à luz da abordagem teórica de Axel Honneth e John Dewey. O objetivo é investigar como as relações comunitárias fortes podem conferir um novo significado à democracia

Metodologia: A metodologia utilizada é dedutiva dialógica; parte-se da perspectiva do conceito de democracia e seus elementos de concreção, participação e cooperação. Para tanto, vale-se de pesquisa bibliográfica para construção e desenvolvimento da pesquisa.

Resultados: Constatou-se que, para o amadurecimento das relações sociais e institucionais, tornar-se-ia importante a formulação de políticas públicas que estimulem a atividade associativa e comunitária por meio do fortalecimento de associações de bairro e conselhos participativos locais, por meio do treinamento de lideranças e engajamento de pessoas para a solução de problemas concretos relacionados ao território. Chama atenção, ainda, para uma democracia mais participativa e 
responsável do indíviduo para o coletivo, o que se pode experimentar com um modelo cooperativo de resolução de problemas.

Contribuições: As principais contribuições trazidas por este estudo tangenciam a releitura do conceito de democracia, um modelo que exija mais a participação e cooperação da sociedade a fim de propiciar uma efetiva emancipação. Assim, o artigo contribui com a análise de aspectos teóricos e sua aplicação pragmática no que tange o modelo democrático. Por fim, uma contribuição que não pode deixar de ganhar destaque é a perspectiva de uma democracia a partir da responsabilidade participativa do indivíduo em favor do coletivo, o que exige ato de cooperação mútua a fim de fortalecer a democracia.

PALAVRAS-CHAVE: Democracia; cooperação; participação; integração social; cidadania.

\section{ABSTRACT}

Objective: The article addresses the relationship between democracy, cooperation and citizenship in the light of the theoretical approach of Axel Honneth and John Dewey. The goal is to investigate how strong community relations can give new meaning to democracy.

Methodology: The methodology used is dialogical deductive, starting from the perspective of the concept of democracy and its elements of concreteness, participation and cooperation, making use of bibliographic research for construction and development of research.

Results: It was ascertained that for the development of social and institutional relations, it would be important to formulate public policies that stimulate associative and community activity through the strengthening of neighborhood associations and local participatory councils, by way of training, leadership and engagement of people to solve concrete problems related to the territory. It also draws attention to a more participatory and responsible democracy of the individual to the collective, which can be experimented with a cooperative problem-solving model.

Contributions: The main contributions brought by this study relate to the rereading of the concept of democracy, a model that requires more the participation and cooperation of society in order to provide an effective emancipation. The article contributes to the analysis of theoretical aspects and their pragmatic application regarding the democratic model. Finally, a contribution that has to be highlighted is the perspective of a democracy based on the participative responsibility of the individual in favor of the collective, which requires an act of mutual cooperation in order to strengthen democracy. 
KEYWORDS: Democracy; cooperation; participation; social integration; citizenship.

\section{INTRODUÇÃO}

Não resta dúvida de que democracias maduras são tributárias da garantia de um conjunto amplo de direitos de cidadania, especialmente os que asseguram acesso amplo e igualitário a espaços institucionais de participação e deliberação. Da mesma maneira, não se questiona que democracias fortes estão mais protegidas de práticas de corrupção, seja porque cidadãos participativos exercem mais eficazmente o controle social dos atos do Poder Público, seja porque o relacionamento inverso - do Estado em direção à sociedade civil - está baseado numa postura calcada numa noção consolidada de accountability (ou confiança) - num sentido bilateral que inibe uma relação predatória mútua entre esses dois atores.

O consenso em torno dessas questões é tamanho que nos últimos 30 anos o receituário básico para resolver problemas de nações marcadas por fragilidades institucionais tem sido o binômio participação e controle social/observância das regras legais pelos Estados. Ocorre que essa solução é, por excessivamente geral, incapaz de lidar com problemas práticos de sociedades marcadas por processos de integração profundamente desiguais ou por relações de dominação imemoriais.

Dito de outro modo, o foco conferido às soluções institucionais trouxe como consequência negativa uma atenção menor ao elemento humano. E a democracia só faz sentido se ajudar as pessoas a resolverem problemas práticos. Olhar para os seus destinatários é urgente, para que as soluções teóricas não se tornem meros exercícios retóricos ou proposições frias, que desconsideram as condições preexistentes de relações sociais.

A crítica faz sentido: se a realidade é em tudo incompatível com o modelo normativo de democracia, qual é a sua relevância, afinal?

Para lidar com essas e outras questões, é preciso sair lentamente da interface institucional e jurídica das democracias e caminhar em direção ao seu aspecto humano. Isso não significa abandonar a opção por arenas democráticas mais sólidas 
e juridicamente bem arquitetadas. Mas passa, com segurança, por olhar para as pessoas: o componente humano da democracia, que, por evidente, Ihe constitui e, mais do que isso, the confere significado.

Aliás, mesmo a ideia de accountability se beneficia desse outro olhar. E, por consequência, o combate à corrupção. Para tanto, é preciso reconhecer que a falta de confiança nas instituições e a corrupção são sintomas que partilham a mesma raiz: sociedades cuja organização política estatal não inclui os cidadãos, não Ihes valoriza e, com isso, acabam fomentando uma relação degradada entre ambos, como é o caso do quadro existente no Brasil. Nesse diapasão, a corrupção pode aparecer, por exemplo, como um ato de resistência frente a uma relação marcada por injustiças e desmandos do Estado em relação à sociedade civil. Seja aquela praticada pelo particular em relação a entidades públicas, seja aquela operada de dentro dessas mesmas instituições por agentes políticos.

Como produzir uma integração social e uma política mais imunes a essas armadilhas é o desafio da breve reflexão aqui desenvolvida. Ela se dará a partir das contribuições teóricas do filósofo alemão Axel Honneth e também de seu colega norteamericano John Dewey.

A proposta, nesse sentido, é analisar a etapa pré-política da participação social. A ideia é verificar as relações comunitárias antes da etapa de formulação de temas para o debate público, a fim de identificar se os processos de integração social, na forma de laços sociais fortes, influenciam a etapa seguinte de forma positiva.

O estudo, conceitual, espera obter como resultado a iluminação de uma dimensão pouco explorada da participação social, com vistas a desatar os nós que impedem 0 amadurecimento social, institucional e político, em prol do aperfeiçoamento da democracia, inclusive no Brasil. 


\section{PARA COMEÇO DE CONVERSA: A DEMOCRACIA COMO COOPERAÇÃO REFLEXIVA}

Para desenvolver sua teoria democrática, Axel Honneth retorna às ideias do filósofo norte-americano John Dewey, e sua proposta de uma democracia como reflexo da cooperação comunitária. O debate é importante na medida em que tenta aproximar duas vertentes da filosofia política contemporânea que estão hoje na posição de adversárias no campo das ideias: o comunitarismo e o procedimentalismo. A democracia, para ele, começa em casa, e se desdobra em pequenas comunidades. A ideia normativa de democracia, por isso, é uma ideia social, em que a rede social é incumbida do exercício de um papel regulador, um metabolismo próprio das redes sociais.

Dewey se apresenta como um autor preocupado em valorizar a democracia enquanto expressão comunitária, em que a associação deixa de ser a noção de que há um medium entre Estado e Sociedade, ou, como a modernidade convencionou, decorrência de um contrato social, de uma estrutura racionalizante da qual deriva a soberania e o fundamento teórico do próprio Estado. Nem mesmo seria consequência de uma externalidade previsível, proveniente de um mecanismo político cujo funcionamento vem da previsão de que os cidadãos são indivíduos minimamente cumpridores de seus direitos de cidadania.

Para o filósofo norte-americano, a associação é a expressão coletiva de indivíduos para quem a democracia é um modo de vida, que se opõe à noção de uma mera "democracia política", ou seja, que reside no íntimo universo das convicções de um indivíduo que a cultiva e que molda sua ação social e suas atitudes no amálgama comunitário. Tal amálgama, por sua via, não é apenas uma coletividade de indivíduos. É, em realidade, a expressão de uma atividade conjunta que, ao produzir consequências boas para os participantes a ponto de ser preservada e constantemente estimulada nos exatos termos de ser um bem compartilhado por todos, se configura como comunidade. 
Nela, os conceitos de liberdade, igualdade e fraternidade não existem isoladamente, posto que seriam abstrações inúteis. Por isso, não se pode imputar às ideias de Dewey a pecha de uma defesa incondicional da autonomia individual sobre tudo e todos ${ }^{1}$. O que ele pretende, ao contrário, é reforçar a ideia de comunidade a partir da noção de indivíduo, o que faz todo sentido quando se pensa a questão da luta por reconhecimento.

Dewey entende também que a democracia, para além de modelos formais, consolida-se na medida em que afeta as formas de associação humana, como a família, a escola e a religião. A dimensão institucional, centrada no Estado, acaba tendo um valor reduzido, devendo, somente, servir de canal para operação efetiva dessa afetação societária. Assim, reduz-se o que Dewey denomina "santidade do sufrágio" enquanto um fim em si próprio. Levado ao limite, isso representa o solapar da democracia, pois ela é expressão da vida em comunidade e não o contrário. E significa um redimensionamento das categorias que marcaram a modernidade iluminista: igualdade, liberdade e fraternidade. Com ele:

\begin{abstract}
A liberdade é aquela liberação e realização segura das potencialidades pessoais que ocorrem somente na rica e múltipla associação com outros: 0 poder para ser um ser individualizado fazendo uma contribuição distintiva e desfrutando, do seu próprio modo, dos frutos da associação. A igualdade denota a parte não-tolhida que cada membro individual da comunidade tem nas consequências da ação associada. Ela é equitativa, porque é medida apenas pela necessidade e capacidade de utilizar, não por fatores extrínsecos que provam um para que outro possa tomar e ter. Um bebê na família é igual aos outros, não por causa de alguma qualidade anterior e estrutural que é a mesma dos outros, mas na medida em que suas necessidades de cuidados e desenvolvimento sejam atendidas sem serem sacrificadas à força superior, posses e capacidades amadurecidas dos outros (DEWEY, 2008, p.56).
\end{abstract}

O conceito de comunidade, assim, transcende a noção de "associação de muitas pessoas". É maior do que isso, na medida em que a comunidade, composta

\footnotetext{
${ }^{1}$ Dewey sinaliza, nesse sentido, que: "aprender a ser humano é desenvolver, através da troca da comunicação, um sentido efetivo de ser um membro individualmente distinto de uma comunidade; alguém que entende e percebe suas crenças, desejos e métodos e que contribui para uma nova conversão dos poderes orgânicos em relação a recursos e valores humanos.". Assim, "o problema é moral e depende de inteligência e educação" (DEWEY, 2008. p. 60).
} 
por seres que observam e pensam, têm interesses e sentimentos, só existe em razão de uma combinação de ações individuais, pautadas em habilidades e capacidades, cujas consequências são percebidas coletivamente e se tornam objeto de comum desejo e esforço de cada um. É o que Dewey (2008, p.57) sustenta quando afirma que "eu e meu entram em cena somente quando uma parte distintiva na ação mútua é conscientemente afirmada ou reivindicada", ou seja, quando há uma relação de organicidade, de estima mútua, que tem na comunicação um pré-requisito.

Afirmar isso é dizer que o atributo inato do homem é a comunicação, que permite a ele interagir e dar sentido efetivo de ser alguém individualmente percebido numa dada comunidade. Somente nesse locus é que fazem sentido os avanços tecnológicos, os acréscimos de conhecimento oriundos da ciência, a evolução do mundo do trabalho, pois são frutos da ação associativa do homem. Para não representar formas de opressão, devem estar articuladas com esse conceito particular de comunidade.

A citação é extensa, porém extremamente central: a opressão surge, para Dewey, dado que:

As habituações emocionais e as habitudes intelectuais da massa de homens criam as condições das quais os exploradores de sentimento e opinião apenas tiram proveito. Os homens se acostumaram a um método experimental em questões físicas e técnicas. Eles ainda tem medo disso em interesses humanos. O medo é ainda mais eficaz porque como todos os medos enraizados, ele é encoberto e disfarçado por todos os tipos de racionalizações. Uma de suas formas mais comuns é a idealização verdadeiramente religiosa das - e reverência pelas - instituições estabelecidas; por exemplo, em nossa própria política, a Constituição, a Suprema Corte, a propriedade privada, a liberdade contratual, e assim por diante. As palavras "sagrado" e "santidade" vem prontamente aos nossos lábios quando tais coisas entram em discussão. Elas comprovam a auréola religiosa que protege as instituições. Se "sagrado" significa aquilo que não deve ser aproximado nem tocado, exceto com precauções cerimoniais e por pessoas especialmente escolhidas, então tais coisas são sagradas na vida política contemporânea. À medida que as questões sobrenaturais tem sido progressivamente abandonadas numa praia deserta, a realidade dos tabus religiosos tem cada vez mais se concentrado em torno das instituições seculares, sobretudo aquelas ligadas ao Estado nacionalista. Os psiquiatras descobriram que uma das causas mais comuns de distúrbio mental é um medo subjacente do qual o sujeito não está ciente, mas que leva à retirada da realidade e à relutância de refletir sobre as coisas. Há uma patologia social que trabalha poderosamente contra a investigação efetiva sobre as instituições e condições sociais. Ela se manifesta de mil maneiras; em 
rabugice, em divagação impotente, no ato desconfortável de agarrar-se a distrações, na idealização do estabelecido há muito, em um otimismo fácil assumido como um disfarce, na glorificação desenfreada das coisas "como elas são", na intimidação de todos os dissidentes - maneiras que deprimem e dissipam o pensamento tanto mais eficazmente porque elas operam com uma penetração sutil e inconsciente (DEWEY, 2008, p.71).

Essa passagem evidencia uma interessante similitude entre o pensamento de Dewey e dos autores da Escola de Frankfurt. Ainda que com nomenclaturas diferentes, percebe-se, aqui, o uso de conceitos como: razão instrumental, bloqueio ao processo emancipatório, esfera pública, ação comunicativa e, principalmente, as formas mais sutis de desrespeito contidas nas dimensões de reconhecimento de Honneth, enquanto atuantes no seio da comunidade na forma de obstruções às formas positivas de sua dinâmica interna.

\section{A COOPERAÇÃO COMO ELEMENTO “PRÉ-POLÍTICO”}

Toda essa reflexão deságua numa conclusão importante: a democracia não pode prescindir de um amálgama social pré-político. Pré-político significaria, nesses termos, a etapa anterior ao momento em que os indivíduos se lançam em discussões públicas de acordo com seus interesses e pretensões políticas. A democracia, assim, para Dewey (1939, p.139):

[...] como um modo de vida pessoal e individual não envolve algo fundamentalmente novo. Mas quando aplicada, ela confere um novo sentido prático a velhas ideias. Colocada em prática, ela significa que os inimigos poderosos atuais da democracia podem ser confrontados com sucesso apelas pela criação de atitudes pessoais nos seres humanos individuais. Que devemos superar nossa tendência de pensar que sua defesa pode ser encontrada em meios externos quaisquer, sejam civis ou militares, se eles estiverem separados de atitudes individuais arraigadas a ponto de construir o caráter pessoal. A democracia é um modo de vida guiado por uma fé ativa nas possibilidades da natureza humana. A crença no homem comum é um item familiar ao credo democrático.

É a crença de que, mesmo em cenários nos quais os indivíduos não possuam horizontes de objetivos iguais, a cooperação pode assumir a forma de uma 
colaboração amigável como um acréscimo imprescindível aos projetos de vida dos envolvidos. Nesse contexto, as disputas podem ser solucionadas na forma de um aprendizado cooperativo em que cada envolvido confere ao outro a chance de se expressar ao invés de ver prevalecer uma dada opinião com base na força e na coerção, ou, nas palavras de Dewey, nas formas de supressão à força através da violência, em que são empregados "meios psicológicos de ridicularização, abuso, intimidação" (DEWEY, 1939, p.148).

A grande contribuição de Dewey, então, está na adição dos conceitos de associação e comunidade como pré-requisitos à democracia. Associação, aqui, tem o sentido de um deslocamento do lugar da democracia, que sai da esfera estritamente estatal - ideia que, como visto, é partilhada por Axel Honneth - para o seio das relações sociais, consideradas desde a relação entre vizinhos até as grandes comunidades, e o sentido também de um modo de vida pautado no viver junto.

Comunidade, por sua vez, deixa de ser uma metáfora contratualista para passar por um processo de resignificação dinâmica, que nasce da pura associação humana na presença da liberdade para então representar uma nova forma de organização humana. Fecha-se, assim, o dualismo Estado-Sociedade civil, ao "se constituir simultaneamente como os dois sem, todavia, ser nenhum deles" (DEWEY, 1939, p.148). Em comum, ambas as categorias desembocam na formação de um projeto democrático radical, já que a democracia passa a ser um modo de vida cooperativo, autogovernado e autodeterminado.

A síntese oferecida por Thami Pogrebinschi (2008) é valiosa:

Em sua vocação experimentalista, o pragmatismo de Dewey concilia experiência e futuridade, buscando constituir-se como um pensamento do presente. $O$ consequencialismo e o contextualismo endossados pelo pragmatismo convergem em uma concepção experimental da política na medida em que conciliam uma abordagem instrumentalista das instituições e uma orientação para o futuro com os valores e crenças afirmados na prática da experiência cotidiana dos homens comuns. Esse ponto de convergência leva a mais um atributo que o pragmatismo tem a oferecer ao conceito de democracia: a reflexividade. Em sua vocação reflexiva, o pragmatismo concilia falibilismo e responsividade. $\mathrm{O}$ falibilismo defendido pela democracia deweyana implica aceitar que um arranjo político que espelhe um valor ou reflita uma crença em um determinado momento possa ser falsificado em um momento seguinte, na medida em que valores e crenças são mutáveis e 
revisáveis e os hábitos da mente que levam os homens à ação são dinâmicos e não estáticos. O caráter revisável dos valores e crenças responde, por sua vez, pela responsividade do pragmatismo. A democracia implica na responsividade das instituições e arranjos políticos na medida em que os homens que respondem por elas são seres reflexivos e, portanto, capazes de converter sua falibilidade pessoal em um esforço permanente de aperfeiçoamento das suas formas de vida (DEWEY, 2008, p.151).

Tais ideias são fundamentais para compreender a proposta de Honneth. A uma, como dito, porque a democracia ganha, com ele, um fundamento pré-político importante. A duas, porque, sem o elemento individual, ou sua expressão coletiva da associação, pouco sentido faz se pensar em uma democracia participativa, inclusive em termos da divisão social do trabalho, que deve ter sua regulação realizada de forma tal que não interfira no dever de participação do indivíduo na associação de que faz parte.

Os estudos de John Dewey, como visto, apresentam uma abordagem bastante peculiar em torno da questão democrática, sobretudo porque esta difere, substancialmente, de boa parte da teoria contemporânea predominante da democracia. Honneth enxerga aí a chave para superar os principais dilemas e aporias das formulações de seus antecessores e daqueles que modernamente se debruçaram sobre essa questão, e dedicou um texto, publicado em 1998, a respeito da atual teoria democrática.

De acordo com o filósofo alemão, a discussão recente sobre a democracia radical é marcada por uma polarização entre republicanismo e procedimentalismo. Em linhas gerais, tais modelos se propõem a lidar com os défices de participação do liberalismo clássico, em especial a partir de fórmulas que garantam maior participação dos indivíduos nas deliberações políticas, embora a partir de perspectivas sensivelmente distintas: no republicanismo, a tônica se concentra na negociação intersubjetiva de questões públicas como um atributo da vida nas cidades, enquanto no procedimentalismo o foco está na adoção de procedimentos moralmente justificados.

Para Honneth, contudo, esse predomínio, ainda que represente um acréscimo, trouxe consigo um efeito negativo, que se concentra no fato de que, a rigor, 
parece não haver outra alternativa normativa na tarefa de atualização permanente da democracia. Nesse sentido, ele sugere a adoção da teoria democrática de John Dewey como uma terceira via; à primeira vista, não há qualquer impossibilidade no sentido de harmonização das hipóteses em jogo, já que, para o filósofo alemão, a contribuição de Dewey pode ser vista como um antecedente teórico das duas abordagens.

Com ele:

\begin{abstract}
Não é difícil para o republicanismo político se referir a elementos da teoria democrática de Dewey porque ela também está baseada na ideia de uma integração de todos os cidadãos em uma comunidade auto-organizada. Contudo, por sua vez, a teoria procedimentalista de democracia também não tem dificuldades de se remeter às concepções de Dewey, já que para ele os procedimentos racionais de resolução de problemas são elemento central do estudo da esfera pública (HONNETH, 2001, p.66).
\end{abstract}

Ao lançar essa assertiva, Honneth se propõe a explorar em que medida os argumentos das outras abordagens teóricas a respeito de seus próprios fundamentos estão equivocadas. Para realizar esse esforço argumentativo, ele procurou apontar como a adoção de um ponto de vista parcial das ideias de Dewey, por parte das duas correntes contemporâneas da democracia, se dá de forma equivocada. Nesse sentido, ele apresenta a opção, encontrada no interior do pensamento deweyano, de uma cooperação social que, na prática, se distancia de uma noção de consulta comunicativa: "Porque Dewey deseja entender a democracia como uma forma reflexiva de cooperação, comunitária - eis minha tese de forma resumida - ele é capaz de combinar deliberação racional e comunidade democrática" (HONNETH, 2001, p.67).

Para Honneth, as correntes atuais da democracia radical conferem interpretação negativa à liberdade individual. Tal posição é tributária tanto da tradição marxista ${ }^{2}$ quanto daquela que remonta a Alexis de Tocqueville, que entendiam que a perspectiva liberal de política reduzia-se à legitimação periódica da ação estatal

\footnotetext{
${ }^{2}$ Aqui como desenvolvimento de uma democracia como associação livre de produtores, pautados pela liberdade comunicativa e orientada para motivar a cooperação ao desenvolvimento de capacidades socialmente úteis.
} 
através do voto e à visão de que o Estado cingia-se à proteção das liberdades individuais. Nesse quadro, pouco importava o processo de integração social, mas apenas um debate livre mínimo sobre aquilo que demandava alguma decisão.

As alternativas contemporâneas a esse quadro, por sua via, têm apostado na dimensão comunicativa, na qual a autonomia do cidadão, antes de se fundar num pressuposto de liberdade individual, estava umbilicalmente vinculada à sua associação com outros cidadãos. A democracia emergiria, assim, como um modelo calcado em situações comunicativas de interação livre de dominação.

O detalhamento dessas propostas, que compartilham o núcleo comum indicado no parágrafo anterior, exigiria, porém, um detalhamento acerca do que se entende por liberdade comunicativa. De acordo com Honneth (2001, p.69):

\begin{abstract}
A depender de como o aumento da liberdade por meio das associações sociais é caracterizado, a ideia de um amoldar em comum da política necessariamente se mostra de forma diferente. Nos dois desenhos de democracia até agora identificados como alternativas ao liberalismo clássico, a liberdade comunicativa dos seres humanos é vista da mesma maneira, isto é, de acordo com o modelo do discurso intersubjetivo. Em Hannah Arendt e Jürgen Habermas - só para mencionar, por um lado, a principal representante do republicanismo político, e, por outro, o do procedimentalismo democrático - a ideia de formação democrática da vontade política origina-se da noção de que o indivíduo só atinge liberdade no reino público constituído pela argumentação discursiva.
\end{abstract}

Embora concorde com a importância desempenhada pela intersubjetividade discursiva, Dewey - aqui partilhando da tradição que remonta a Marx - entende que a liberdade comunicativa associa-se mais ao emprego comum de forças individuais para compreender e superar um problema. Por conseguinte, o autor entende que a democracia não pode ser vista como tradicionalmente e instrumentalmente o é, ou seja, como mera forma de organização do Estado em que há uma regra aritmética (a regra da maioria) para organizar a massa disforme de indivíduos isolados e com fins divergentes. Frise-se, nesse caminho, que tal perspectiva instrumental guarda parentesco com as teorias contratualistas clássicas, que adotam uma hipotética situação original de não comunicação e isolamento como fomento para os regimes democráticos. 
Esse fundamento é tido como irreal, abstrato e ficcional. Para superá-lo, Dewey apresenta um conceito de sociedade profundamente influenciado pelo pensamento do jovem Hegel, no qual

\begin{abstract}
A intersubjetividade, em cuja armação a vida social se desdobra, é apresentada de acordo com o modelo de um "organismo social" no qual cada indivíduo contribui por meio de sua própria atividade para a reprodução do todo. O primeiro fato que caracteriza todo tipo de sociabilidade é a existência de cooperação; porém, indivíduos desorientados ou contingentes relacionamse pela busca, baseada na divisão do trabalho, de atividades que conjuntamente contribuem para a manutenção da sociedade. Se a vida social é apresentada conforme tal modelo, então Dewey aponta consequências para o conceito de autonomia pessoal, como também para o de governo político. Ambos têm de ser concebidos como relacionados porque, com a realidade de cooperação social, existe um tipo de bem compartilhado no qual a liberdade individual e a política de Estado devem ser concebidas como suas incorporações opostas, pois cada membro da sociedade contribui, em virtude da divisão de trabalho, por meio de suas próprias atividades para a manutenção da sociedade, ele representa uma "incorporação vital" dos fins da sociedade (HONNETH, 2001, p.71).
\end{abstract}

Dewey ilustra essa perspectiva com o sucesso verificado pela revolução americana, na qual a soberania popular foi incutida no interior de cada cidadão. Isso serve para ilustrar a própria concepção de Estado dada pelo referido autor: a de ser a instituição política de execução da vontade do povo, tido como inserido em relações de cooperação social. Essa ideia pouco difere das concepções clássicas de Aristóteles e Platão acerca de uma comunidade política; a diferença, porém, é central, pois, ao invés de os cidadãos atingirem a liberdade por meio de uma autorrealização bem-sucedida conforme os fins éticos que constituem a eticidade do Estado (o que indica uma relação de finalidade), para Dewey o foco deve estar nos meios de constituição política.

Surge aí mais um indício de que, para Honneth, o direito tenha um papel importante mas limitado na coordenação da vida social, na medida em que a sociedade não pode ser vista, em sua complexidade, pela visão contratual que remonta a Rousseau e Hobbes.

Ao mesmo tempo, fica clara a presença do pensamento de Hegel, pois a noção de "organismo social" abastece o sistema da "totalidade" como expressão de 
uma sociabilidade que só surge como fruto da cooperação. Então, se a origem da democracia como cooperação reflexiva está na liberdade (enquanto expressão de autorrealização positiva e ilimitada com fins de colaboração) e na interação orgânica dos indivíduos, o Estado é compreendido como a instituição política responsável pela execução da vontade que surge desse tecido de relações sociais.

Inverte-se, assim, a lógica aristocrática clássica da centralidade de um grupo de indivíduos talentosos poder atingir o ideal ético, pois todos os cidadãos podem, com base em sua vontade livre, aperfeiçoar-se na busca do bem, mantendo com seus pares uma relação de confiança recíproca na qual cada um é sabedor de sua função social. Para Honneth, essa noção clarifica a posição de Dewey a respeito do entrelaçamento entre cooperação, liberdade e democracia, pois ele

\begin{abstract}
Percebe a existência de uma divisão social do trabalho como evidência do fato de o indivíduo dever sua liberdade pessoal somente à comunicação com os outros elementos da sociedade. Liberdade para Dewey é principalmente a experiência positiva de autorrealização ilimitada que ensina ao indivíduo como descobrir seus talentos e suas capacidades por meio dos quais ele pode, no fim, contribuir com base na divisão de trabalho, para a manutenção do todo social. Se esse processo natural de um emprego comunal de forças individuais por parte dos integrantes de toda a sociedade é conscientizado e visto como um projeto cooperativo, então se evolui para o ideal de "democracia" (HONNETH, 2001, p.74).
\end{abstract}

Como dito no decorrer desta reflexão, o grande trunfo explorado por Dewey e aproveitado, no contexto da luta por reconhecimento, por Axel Honneth, é o elemento pré-político da democracia, a qual é mantida numa perspectiva estritamente teórica, sendo difícil, porém, não perceber problemas ou dificuldades nessa abordagem. Afinal, para que a fórmula apresentada por Dewey transcorra sem percalços, é necessário que o ideal de autorrealização individual esteja fundado em um direcionamento que motive o desenvolvimento de capacidades socialmente úteis, o que cria um obstáculo para Dewey no sentido de estabelecer uma institucionalização política da liberdade.

A questão encontra solução nos estudos psicológicos. Dewey reconhece a influência exercida por Hegel em suas teses sobre a democracia, nas quais a centralidade está na autorrealização humana fundada na ausência de 
constrangimentos externos ou influências no percurso até a aceitação voluntária de obrigações sociais. Contudo, se antes havia uma teleologia insustentável da natureza humana a impedir o direcionamento indicado no parágrafo anterior, agora entra em cena a explicitação dos mecanismos sociais que ajudam a compreender, sem influências metafísicas, a compatibilidade social da autorrealização. Nesses termos, de acordo com Honneth (2001, p.78):

\begin{abstract}
A solução que Dewey encontra no curso de sua pesquisa pode ser entendida em termos de uma teoria da intersubjetividade da socialização humana; dos acessos totalmente irrestritos que, no princípio, consistem em uma multidão de impulsos indiretos e formidáveis, os seres humanos podem desenvolver aquelas capacidades e necessidades como hábitos estáveis de ação que foram aprovados e são estimados por um grupo particular de referência. A satisfação propiciada pela realização de certa ação aumenta à medida que 0 cidadão percebe o reconhecimento dos outros em interação. Como todo integrante da sociedade sempre pertence a vários grupos de referência, as camadas sobrepostas de expectativas garantem que no curso do desenvolvimento de uma personalidade apenas hábitos sociais úteis sejam formados. Esse modelo de autorrealização humana, do qual Dewey não renuncia por toda sua vida, também forma o ideal de democracia no livro sobre o público.
\end{abstract}

Tal discussão se dá no interior de uma compreensão da dependência mútua de autorrealização feita com base em estudos sobre o desenvolvimento da personalidade humana. Esses estudos se deram da forma pragmatista, indicada no item anterior, com que Dewey enxerga a função do saber científico, ou seja, como saber orientado à resolução de problemas que causam perturbação. Essa função só pode se concretizar de modo satisfatório se os cientistas cooperam, sem constrangimento, no desenvolvimento de suas hipóteses, o que, ampliado para o espectro social, significa uma valorização dos processos de aprendizagem social, na qual a democracia, ressignificada, é a forma política de organização na qual a inteligência humana, orientada para a solução de problemas emergentes sem constrangimentos para os envolvidos, atinge seu desenvolvimento pleno.

Essa conclusão apresenta grande impacto para este ponto. Afinal, é com ela que Dewey começa a enxergar a importância do conteúdo racional dos procedimentos democráticos. Isso, porém, não dá conta, por enquanto, de reconciliar esse 
pressuposto com a asserção de que a autorrealização individual só é possível em uma comunidade de cooperação. Para responder a essa dúvida, Dewey apresentará seu conceito de "público", assim delineada por Axel Honneth (2001, p.78):

\begin{abstract}
A ideia básica é muito simples, ainda que a implementação da ação teórica nos surpreenda hoje. A ação social desdobra-se em formas de interação cujas consequências, de forma simples, afetam apenas os imediatamente envolvidos, mas assim que os não envolvidos se veem afetados pelas consequências de tal interação, emerge de suas perspectivas a necessidade de controle das ações correspondentes no sentido de sua cessação ou promoção. A articulação da demanda por resoluções conjuntas de problemas comuns constitui para Dewey aquilo que ele chamará de "público". O termo "público" é atribuído à esfera de ação social na qual um grupo pode provar que necessita de regulamentação geral porque consequências não antecipadas estão sendo geradas e adequadamente, um "público" consiste do círculo de cidadãos que, em razão da preocupação conjuntamente experimentada, compartilham a convicção de que eles se devem voltar para o resto da sociedade em busca do propósito de controlar administrativamente uma interação pertinente.
\end{abstract}

Esse conceito, porém, não se afigura isento de eventuais críticas. Com efeito, há uma noção vaga do que se entende por "consequências indiretas das transações", e sobre o grau de afetação daqueles que não se encontram no círculo dos envolvidos diretamente com uma dada questão. De acordo com Honneth, Dewey talvez resolvesse a querela apostando numa proposta de assumir uma diferenciação processual entre "público" e "privado", na qual a distinção entre ambos se vinculasse à extensão e escopo das consequências das ações que demandam o controle público. O Estado, assim, representaria, por decorrência lógica, uma instância de associação secundária na qual inúmeros públicos, irmanados no objetivo de articulação de uma sociedade cooperativa, tentassem solucionar problemas imprevistos no contexto da ação social.

Até aqui, pode-se dizer que Dewey se esforçou para, dentro da sociedade cooperativa, dar os contornos da ação política. Tal construção difere em grande medida daquela, realizada por Hannah Arendt e Habermas, que dão à ação política o papel de local de exercício comunicativo da liberdade. Dewey, ao contrário, dá um passo atrás que se revela como um meio cognitivo que auxilia a sociedade a realizar, 
por meio de experiências, explorar e resolver seus problemas de coordenação da ação.

O ambiente democrático é, assim, o melhor espaço para produzir esse efeito desejado, pois no processo de aprendizagem social, no contexto da cooperação, há maior potencial para propiciar a emergência de uma esfera pública de proponentes que podem introduzir suas hipóteses, convicções e intuições, sem constrangimentos e com direitos iguais. Essa visão decorre de um diagnóstico do tempo em que, para Dewey, observa-se,

Como resultado da industrialização, do crescimento de complexidade e da individualização, as sociedades modernas encontram-se em um estado de desintegração que faz com que ideias de uma participação de todos os cidadãos em esferas públicas democráticas pareça ilusória. (...) Para Dewey, está além de dúvidas que, para todos os cidadãos serem orientados pelos procedimentos democráticos de resolução de problemas políticos, deve ser pressuposta uma forma de associação pré-política como as existentes nas comunidades pequenas, facilmente observáveis, dos distritos municipais americanos (HONNETH, 2001, p.81).

Guardadas as proporções temporais, pode-se afirmar que esse diagnóstico possui grandes semelhanças com o momento presente, o que faz do quadro esboçado por Dewey um elemento de grande valor para compreender os dilemas das sociedades democráticas contemporâneas. A solução apontada por ele, então, também pode ser aproveitada ao passo que os integrantes de uma sociedade têm oportunidade de compreender o sentido da democracia ao observarem a convergência de suas ações cooperativas em direção a uma meta comum, uma consciência comum que vai em direção ao elemento pré-político.

\section{4 À GUISA DE CONCLUSÃO: A COOPERAÇÃO REFLEXIVA E $O$ AMADURECIMENTO DAS RELAÇÕES SOCIAIS E INSTITUCIONAIS}

O desafio, então, caminharia da instituição de espaços institucionais para a formulação de políticas que estimulem a atividade associativa e comunitária por meio 
do fortalecimento de associações de bairro e conselhos participativos locais, por meio do treinamento de lideranças e engajamento de pessoas para a solução de problemas concretos relacionados ao território.

Curiosamente, a semente desse processo já se encontra plantada na própria maneira como certos bairros - e em especial aqueles localizados nas franjas da cidade, em porções marginalizadas e de ocupação informal - se organizam socialmente. Neles, a cooperação é um elemento importante para a sobrevivência em meio à privação. Mesmo a dinâmica da autoconstrução, que acompanha a urbanização brasileira com mais força desde a segunda metade do século XX, é um exemplo de ação espontânea no sentido do fortalecimento dos laços comunitários. Tais exemplos têm muito a ensinar à estruturação de uma política pública de participação mais compreensiva e menos formalista.

É, em síntese, a própria noção de procedimento democrático com uma função de resolução cooperativa de problemas. Assim, expandida para a vida pública,

Orientar-se por procedimentos democráticos pressupõe uma forma de vida ética democrática que não é ancorada em virtudes políticas, mas na consciência da cooperação social. Nesse sentido, Dewey pode alegar que as três máximas orientadoras da Revolução Francesa normativamente expressam os ideais que, mediante formas democráticas e justas da divisão de trabalho, estão localizadas em uma associação pré-política (HONNETH, 2001, p.86).

O que importa, para Dewey, é exatamente o processo experimental no qual a sociedade processa e resolve seus problemas, de um ponto de vista racional. Se isso, de um lado, o aproxima de Habermas, de outro o afasta, pois, se Habermas considera que a esfera pública é o espaço privilegiado para que mesmo os excluídos tenham a chance de, por garantia normativa, tentar superar sua condição de marginalizados, o elemento social, para ele, torna-se um problema. Afinal,

Onde Dewey considera o estabelecimento de formas justas, cooperativas da divisão de trabalho, como uma exigência normativa que, por causa das condições funcionais dos públicos democráticos e completamente independente do estado de lutas por reconhecimento, é em princípio válida e assim um componente interno de toda a ideia genuína de democracia, 
Habermas não pode colocar conceitualmente a demanda por igualdade social antes do princípio da formação democrática da vontade política, mas tem de fazê-la dependente da contingência das metas politicamente articuladas. Por causa dessa restrição unilateral da democracia ante a esfera política, perdese a noção do fato de uma esfera pública democrática só poder funcionar na premissa tácita de uma inclusão de todos os integrantes da sociedade no processo de reprodução social. A ideia da esfera pública democrática está baseada em pressuposições sociais que só podem ser concebidas fora dos argumentos dessa própria ideia (HONNETH, 2001, p.88).

Daí, inclusive, o apontamento de Honneth em referência aos estudos de seu mestre Habermas, de que estes padecem de um déficit sociológico, exatamente pela "questão social" ou o pressuposto individual de motivação ser um problema do estudo "político" de Habermas, que tende a colocar a formação democrática da vontade política antes da demanda por igualdade social, ou então de fazê-la contingente das metas políticas articuladas.

Em síntese:

[...] a esfera pública democrática está baseada em pressuposições sociais que só podem ser concebidas fora dos argumentos dessa própria. Ela espera que cada cidadão compartilhe tantas áreas de interesse concordantes que pelo menos uma motivação possa emergir para permitir o envolvimento do cidadão em negócios políticos. No entanto, tal grau de concordância só pode evoluir onde, no domínio pré-político, já havia sido possível vivenciar ligações comunicativas $^{3}$.

Trata-se, por fim, de uma proposta concatenada com a produção democrática baseada na experiência individual de relações cooperativas, que atende tanto a sociedades em desenvolvimento quanto às que experimentam o crepúsculo do modelo industrial. Isso faz da teoria da democracia enquanto cooperação reflexiva mais do que uma reestruturação normativamente inspirada do capitalismo; torna-a

\footnotetext{
${ }^{3}$ HONNETH, 2001, p. 89. Os sentimentos relacionados às experiências de desrespeito devem, assim, ganhar profundo relevo nas demandas normativas, acima dos procedimentos deliberativos formais de construção dialógica de consensos. Essa é a conclusão a que chega o filósofo norte-americano David Owen: “(...) nem a concepção republicana de democracia, nem a procedimental podem ser adequadas para as exigências de autorrespeito e autoestima. Somente um ideal político de democracia radical que combine um compromisso com a garantia de procedimentos democráticos de deliberação racional (isto é, condições máximas da experiência do reconhecimento-respeito) com o compromisso com uma comunidade política democrática (isto é, a condição máxima da experiência de reconhecimento-estima) é capaz de satisfazer ambas as necessidades humanas". (OWEN, 2007, p. 305. Apud BUNCHAFT, 2009, p. 148).
} 
parte de um projeto de redefinição de longo alcance e, por isso, radical, de reprodução social.

Dito de outra maneira, o olhar cuidadoso ao elemento humano da democracia é a chave para a emancipação. Uma vez incorporada pela teoria democrática a dimensão humana e social dos processos de integração social que são o amálgama da democracia, entende-se que a teoria estará dando uma contribuição decisiva ao aperfeiçoamento das práticas democráticas.

\section{REFERÊNCIAS}

BUNCHAFT, Maria Helena. Entre cooperação reflexiva e democracia procedimental. In: Revista Sequência, n. 59. Florianópolis: Universidade Federal de Santa Catarina (UFSC), 2009.

DEWEY, John. Em busca da grande comunidade. In: FRANCO, Augusto de e POGREBINSCHI, Thamy. Democracia Cooperativa - Escritos políticos escolhidos de John Dewey. Porto Alegre: EDIPUCRS, 2008. p. 56.

. Democracia criativa: a tarefa diante de nós. 1939.

FRANCO, Augusto de e POGREBINSCHI, Thamy. Democracia Cooperativa Escritos políticos escolhidos de John Dewey. Porto Alegre: EDIPUCRS, 2008.

Direito e Democracia v. 2. Trad. Flávio Beno Siebeneichler. Rio de Janeiro: Tempo Brasileiro, 2003.

HONNETH, Axel. Democracia como cooperação reflexiva. In: SOUZA, Jessé (org.). Democracia hoje - novos desafios para a teoria democrática hoje. Brasília: Editora UnB, 2001. p. 66.

2015.

. O direito da liberdade. Trad. Saulo Krieger. São Paulo: Martins Fontes,

OWEN, David. Reflections on Honneth's Social and Political Ideal. In: BRINK, Bert van den; OWEN, David (Eds.). Recognition and Power: Axel Honneth and the tradition of critical social theory. Cambridge: Cambridge University Press, 2007

WEBER, Max. Economia e sociedade v. 2 - fundamentos da sociologia compreensiva. $4^{a}$ ed. Trad. Regis Barbosa e Karen Elsabe Barbosa. Brasília: Editora UnB, 2012. 